\section{Celular: o gadget da inclusão social para a baixa renda}

\section{Cell phone: the social inclusion gadget for low-income social class}

\author{
Maria de Lourdes Bacha ${ }^{[a]}$, \\ Celso Figueiredo Neto $^{[b]}$, Angela Schaun ${ }^{[c]}$
}

\section{Resumo}

Este trabalho tem como objetivo analisar a importância do celular como fator de inclusão digital e social para a população de baixa renda de São Paulo, capital. O artigo se inicia com breve referencial teórico, seguido da apresentação dos principais resultados e conclusões. Trata-se de um estudo empírico, exploratório descritivo longitudinal feito em duas fases (2006 e 2011), com realização de entrevistas pessoais junto a usuários/proprietários de celular de baixa renda, residentes na cidade de São Paulo, Brasil, selecionados através de amostra não probabilística por conveniência. Embora os resultados a] Pós-doutora em Comunicação e Semiótica pela Pontifícia Universidade Católica de São Paulo (PUC-SP), docente pesquisadora da Universidade Presbiteriana Mackenzie, São Paulo, SPBrasil, e-mail: mlbacha@gmail.com

[b] Doutor em Comunicação e Semiótica pela Pontifícia Universidade Católica de São Paulo (PUC-SP), docente pesquisador da Universidade Presbiteriana Mackenzie, São Paulo, SPBrasil, e-mail: kekofig@gmail.com

[c] Doutora em Comunicação e Cultura pela Universidade Federal do Rio de Janeiro (UFRJ), docente da Universidade Presbiteriana Mackenzie, São Paulo, SP- Brasil, e-mail: angelaschaun@yahoo.com

Palavras-chave: Celular. Consumidor de baixa renda. Inclusão social. 
não possam ser generalizados para o universo de usuários de celular, face à escolha do tipo de amostragem, os resultados permitem admitir que, para a população pesquisada, as mudanças trazidas pelo celular sejam avaliadas positivamente. O celular pode ser classificado como fator contributivo para a inclusão digital e social, impulsionando o indivíduo para o exercício da cidadania ativa, principalmente no que se refere à socialização.

\section{Abstract}

This paper aims at analyzing the importance of the cell phone as a digital and social inclusion gadget for the lowincome population living in São Paulo, Capital. The article starts with a brief theoretical framework, which is followed by the presentation of the main results and conclusion. It is about an empirical, exploratory, descriptive, longitudinal study conducted in two phases (2006 and 2011) and based on interviews with low-income cell phone users/owners living in the city of São Paulo, Brazil, who have been selected in a non-probabilistic sampling by convenience. Even though the results do not refer to the whole universe of cell phone users, due to the type of sampling, results show that according to the population researched cell phones have brought positive changes. The cell phone can be viewed as a major contributory factor to digital and social inclusion, providing the individual with the impulse for exercising active citizenship, especially when it comes to socialization..
Keywords: Cell phone. Low-income consumer. Social inclusion.

\section{Introdução}

O brasileiro, povo comunicativo por natureza, caiu de amores pelo celular. Esse encantamento pode ser visto em qualquer canto do país, onde brasileiros jovens e velhos, pobres e ricos brincam com seus aparelhos obsessivamente. Da rodoviária ao aeroporto, da sala de aula ao estádio de futebol, da reunião de acionistas ao happy hour, o celular é um aparelho onipresente. Este artigo pretende investigar a relação das pessoas 
das classes sociais C e D na cidade de São Paulo com seus celulares e clarificar a percepção de como o celular mudou a vida dessas pessoas. É certo que o acesso à comunicação rápida e prática inclui social e comercialmente usuários que, antes, dependiam de processos mais complexos e custosos para se comunicar, seja pessoalmente, seja via telefonia pública. Os dados que serão apresentados adiante demonstram esse afluxo popular da comunicação celular. A análise mais detida dos dados, contudo, irá denotar algumas descobertas que parecem bastante instigantes, na medida em que descortinam o fascínio das camadas populares com um novo éthos público, o self virtual. Os dados aqui apresentados parecem demonstrar encantamento e certa timidez com esse novo mundo que se abre. $\mathrm{O}$ acesso à telefonia celular, embora hoje nos pareça natural, é um processo relativamente novo, iniciado no governo FHC com as privatizações e ampliado nos anos Lula com a democratização do acesso. A compra e a posse de aparelhos e o relacionamento entre os indivíduos via celular é o resultado dessa popularização, que hoje apresenta números surpreendentes.

O Brasil terminou julho de 2013 com 267,0 milhões de celulares e $134,81 \mathrm{cel} / 100$ habitantes. (TELECO, 2013). Atualmente é o quinto maior mercado de celulares e o quarto maior mercado de mobilidade no mundo (FUTURECOM, 2012). Em 2012, pela primeira vez, mais da metade dos domicílios brasileiros $(51,4 \%)$ apresentou apenas celular como meio de comunicação, conforme a Pesquisa Nacional por Amostra de Domicílios (PNAD) do Instituto Brasileiro de Geografia e Estatística (IBGE, 2013).

O mercado brasileiro de celulares caracteriza-se pela existência de sete holdings: Vivo, Claro, Tim GSM, CorpCo (resultante da união recente de Oi e Portugal Telecom), CTBC Celular, AEIOU e Sercomtel Celular, disputando os usuários novos e os usuários das operadoras rivais. De acordo com a Teleco (2013), a Vivo é a líder no mercado brasileiro, seguida pela Claro, Tim e CorpCo. O público-alvo estudado foi o de baixa renda, estimado em 73\% da população brasileira (OBSERVADOR BRASIL, 2011).

A GfK Brasil (2010) indica que o celular lidera a intenção de troca de aparelhos eletrônicos entre os brasileiros. Os jovens dos 18 aos 24 anos se destacam entre os que têm maior pretensão de adquirir um novo modelo (53\%) com mais diferenciais e funcionalidades, como acesso à internet e câmera acoplada com melhor resolução. Note-se que a pesquisa citada refere-se à troca de aparelhos e não à compra do primeiro exemplar. Isso denota que a experiência inicial com o celular já está consolidada e que o uso desses aparelhos foi satisfatório, na medida em que os usuários desejam trocar seus telefones por aparelhos mais sofisticados. 
Além disso, 78\% dos brasileiros têm intenção de adquirir um smartphone no futuro próximo. Os brasileiros são lideres na intenção de compra do gadget, com percentuais superiores aos russos (73\%) e mexicanos (61\%) (BRASILEIROS..., 2012).

O Ibope Mídia (em conjunto com Gouveia de Souza Consultores e Ebelfoth Group, 2009) mostra que, no Brasil, o celular é muito mais importante para as pessoas do que o computador ou a internet (IBOPE MíDIA, 2009).

\section{Inclusão digital e o consumidor de baixa renda}

O referencial teórico foi desenvolvido abordando-se, principalmente, inclusão digital e social e características do consumidor de baixa renda. A base teórica está apoiada em autores especializados em Teoria do Comportamento do Consumidor (BLACKWELL; MINIARD; ENGEL, 2005; SOLOMON, 2005). Entre os fatores que influenciam o comportamento do consumidor pode-se considerar os externos e os internos. Entre os externos, inegavelmente, as mensagens dos fabricantes e das operadoras de celular constituem um dos aspectos mais importantes. Entre os fatores internos, as relações sociais e as pressões ligadas à autoestima e self podem ser enfatizadas, e também a concepção de atitude como avaliação duradoura, favorável ou não, formada a partir de crenças e sentimentos a respeito de produtos, pessoas, ideias, que levam o indivíduo à predisposição para agir coerentemente com essa avaliação. Atitude é um conceito relevante na compreensão do comportamento dos indivíduos e de como eles realizam suas escolhas.

Vale acrescentar que na escolha do referencial teórico foi dada ênfase para autores que trabalharam inclusão digital e social. Estudiosos como Canclini (1999), Douglas e Isherwood (2004) e Hall (2001), e também as discussões sobre os benefícios ou malefícios da privatização da telefonia no Brasil, fogem do escopo deste trabalho. É pressuposto dos autores que o celular como ferramenta de infocomunicação, ao incluir digitalmente a população com baixa escolaridade, ajuda na inclusão social.

Lemos (2004) lembra que, atualmente, há mais usuários de celular do que internautas no mundo, dado que tende a crescer, sendo que o celular e a televisão (os projetos de TV digital) são vistos como formas de inclusão digital. Nesse contexto, Buzato (2008, p. 325) considera que a inclusão digital denotaria uma faceta do processo de inclusão relacionada 
às tecnologias e relativa a "conceitos como cidadania, dignidade e justiça social". A inclusão digital já não é vista isoladamente, mas como elemento da cidadania e da inclusão social, representando acesso a oportunidades fundamentais para o desenvolvimento das comunidades na era do conhecimento, visto que a sociedade brasileira é desigual no que se refere ao acesso às novas tecnologias de comunicação.

Gouveia (2004) enfatiza que a desigualdade tecnológica, a falta de acesso à informação e a pouca infraestrutura disponível para o desenvolvimento solidário de conhecimento são fatores que colaboram para a marginalidade de parcelas da sociedade e, por isso, o foco principal da inclusão digital não seria a tecnologia em si, mas o alcance desta na vida da população de renda baixa.

Pavão e Lima (2002) partem do princípio de que o pleno exercício da cidadania exige dos indivíduos conhecimento de ciência e tecnologia, especialmente daquelas tecnologias relativas ao cotidiano. São esses conhecimentos que vão garantir um referencial básico, o qual apoiará a tomada de decisões e atitudes nas mais diversas situações da vida dos cidadãos: optar por este ou aquele tipo de tratamento médico, formas de alimentação, de relacionamento sexual, decidir pela aquisição de produtos e aparelhos tecnológicos, escolher um ou outro serviço técnico e assim por diante.

Pode-se ressaltar o papel do celular como tecnologia de infocomunicação (BACHA; VIANNA; SANTOS, 2009; LEX, 2008) e quanto ao modo pervasivo e ubíquo com que permeia o imaginário e o dia a dia dos indivíduos (SPLITZ, 2008). A análise de algumas das implicações trazidas pela centralidade que os telefones celulares adquiriram na vida cotidiana e seu papel na inclusão simbólica dos indivíduos, especialmente dos jovens, foi estudada por Silva (2007), Mazmanian, Orlikowski e Yates (2006) e Sant'Anna e Garcia (2011). Porém, é possível encontrar outras contribuições importantes, incluindo-se uma breve abordagem no âmbito das quatro empresas que dominam o mercado de telefonia móvel no Brasil, a partir da comunicação da marca (LORENZINI; MACHADO, 2011; ROCHA; PEREIRA, 2012).

Quanto à baixa renda, o celular está entre os objetos mais amados por jovens de lares dessa categoria (ARAÚJO; VANZELOTT; LEVY, 2012). Rocha et al. (2011), em estudo com jovens da baixa renda do Rio de Janeiro, identificou cinco valores atribuídos pelos jovens ao consumo de celular: controle dos pais, espaço privado, conectividade, distinção social e símbolo de vida adulta. O celular pode ser considerado como ferramenta de inclusão social e digital (SCHAUN et al., 2009; SIKDAR; VEL, 
2010; TREVISAN, 2005) e na construção de relações do mundo cotidiano, como self estendido (BACHA, SCHAUN, 2011).

Estudo realizado pelo Instituto de Pesquisas e Projetos Sociais e Tecnológicos (IPSOS), em parceria com a Universidade Aberta da Catalunha, verificou que as restrições financeiras interferem significativamente no uso do celular. No caso dos mais jovens, o celular funciona como elemento de status dentro do grupo, sendo um emblema de prestígio e parte fundamental de sua identidade. $O$ celular representa um elemento de organização social e política para os grupos de teatro de rua que, apesar de suas características de mobilidade e de mobilização, ainda exploram pouco o potencial que a telefonia móvel poderia thes oferecer (IPSOS, 2008).

No que diz respeito à caracterização da baixa renda, utilizou-se os trabaIhos de Chauvel e Mattos (2008), Almeida Prado (2008) e Souza e Lamounier (2010). Para Almeida Prado (2008), não há consenso entre os pesquisadores sobre a forma de classificar a população de baixa renda, podendo ser classificada em renda mensal, classe socioeconômica ou segmentos.

Segundo Almeida (2011), o que realmente mudou com relação à baixa renda é o aumento do poder aquisitivo dessas classes e a possibilidade de acesso aos mais diversos bens de consumo, em todos os segmentos: alimentos, saúde, educação, lazer e cultura, entre outros. O novo seria o acesso a produtos e serviços e o desfrutar da experiência do ter ou fazer, já que a posse e a experiência de consumo transformam o consumidor, seus gostos, atitudes e, sobretudo, comportamento. Essa seria uma transformação sem volta, pois esse consumidor com mais conhecimento e experiência se torna mais crítico e exigente, já que sua referência subiu de patamar, e isso é, sem dúvida, uma grande mudança.

Atualmente, segundo Almeida (2011), esse consumidor é um cliente tecnológico, graças particularmente ao celular, que lhe deu essa oportunidade. Isso porque, além de colocá-lo em contato com as pessoas, ele tem acesso à internet e pode baixar músicas e games. Outro exemplo de que o produto ganhou popularidade entre esse público:

Quem já não observou um trabalhador no ponto de ônibus, se divertindo com o seu celular, enquanto espera longas horas por sua condução? É, na realidade, um instrumento lúdico. Contudo, o significado do celular para essa classe é muito particular e especial. Representa certo status. A frequência de troca desses aparelhos é alta. Como é difícil trocar de carro ou de casa, eles trocam de celular. Muitas vezes não conseguem usar todos os recursos, mas não importa. O que realmente interessa é o prazer da 
experiência do novo, do mais atual, do que chama a atenção. O celular democratizou o acesso à tecnologia mais do que o computador e a internet, uma vez que nem todos têm acesso a computador e tão pouco à internet, mas podem comprar um celular high tech (ALMEIDA, 2011, p. 101).

Este artigo utiliza a classificação socioeconômica Critério Brasil, que se refere ao poder de compra de indivíduos e famílias urbanas e baseia-se nas questões: patrimônio, bens duráveis e não duráveis, domicílio, grau de instrução do chefe de família, e outras inseridas nas classes determinadas (ASSOCIAÇÃO BRASILEIRA DE EMPRESAS DE PESQUISA, 2010).

\section{Apresentação e análise de resultados}

O objetivo principal foi analisar as mudanças percebidas na vida dos usuários de baixa renda com o uso do celular como tecnologia de comunicação e informação. Foi realizada pesquisa empírica quantitativa longitudinal junto a uma amostra não probabilística por conveniência (MALHOTRA, 2001) constituída de duas fases e subvencionada pelo Mackpesquisa e pela Fapesp. Na primeira fase, em 2006, foram entrevistados 449 indivíduos e, na segunda, em 2011, 420 indivíduos das classes C e D residentes em São Paulo, possuidores/usuários de telefone celular (selecionados em pontos de fluxo, usando o critério de classificação socioeconômica Brasil).

Como instrumento de coleta de dados foi utilizado o questionário estruturado. O levantamento dos dados utilizou a abordagem da entrevista pessoal. As entrevistas foram realizadas em pontos de fluxo de pedestres, em bairros paulistanos da Zona Leste - Penha, Cangaíba, Arthur Alvin, Itaquera, Guaianazes, São Mateus e Mooca; da Zona Sul - Ipiranga, Sacomã e Jabaquara; e da Zona Norte - Vila Maria. As respostas dos questionários foram digitadas em máscaras de software de pesquisa SPSS. Os dados obtidos foram analisados a partir do cálculo das medidas usuais de posição e dispersão. Os respondentes foram submetidos aos filtros: uso de celular, residência no município de São Paulo e classe socioeconômica C e D (de acordo com Critério Brasil).

\section{Perfil demográfico da amostra}

A Tabela 1 apresenta uma descrição do perfil da amostra estudada segundo gênero, classificação socioeconômica, faixa etária e escolaridade. 
Do ponto de vista do perfil, embora a amostra tenha sido escolhida por meio de critérios não probabilísticos por conveniência, é possível dizer que há indícios de que a posse de celular na população de baixa renda ainda seja predominante nos indivíduos mais jovens e com escolaridade baixa. Na amostra de 2006, 59\% dos entrevistados tinham até o curso médio incompleto e na amostra de 2011 60\%. Mas há um dado que merece atenção, a frequência de uso diário do celular, que variou de 77\% em 2006 para 91\% em 2011, confirmando a tendência de aumento do uso e dependência do celular (SCHAUN et al., 2009).

\section{Posse e uso do celular}

Relativamente à posse e uso do celular, vale destacar que o gasto médio diminuiu, provavelmente em função das ações promocionais das operadoras (de $R \$ 42,39$ em 2006 para $R \$ 37,12$ em 2011). No entanto, o tempo de posse do celular aumentou sensivelmente, como também o número de celulares na residência e o percentual de aparelhos trocados. Mas o que merece ênfase é o percentual de indicação da operadora (64\% em 2006 comparados com 83\% em 2011), como também para quem a operadora seria indicada, principalmente amigos (71\%) e parentes (66\%). Esse é um dado bastante interessante, pois aponta para a lealdade da marca da operadora (embora possa parecer contraditório, considerando-se que as operadoras de telefonia são campeãs de reclamações no Procon). Contudo, considerando que todas as operadoras oferecem planos de gratuidade ou baixas tarifas para ligações entre telefones da mesma operadora, a importância da indicação de parentes e amigos se reveste de uma real vantagem econômica para os usuários. A Tabela 2 detalha os principais resultados referentes à posse e uso de celular.

Cruzamentos entre frequência de uso, posse e uso do celular e as demais variáveis de perfil dos respondentes revelaram a não existência de diferenças estatisticamente significativas.

\section{O celular: comunicação e socialização}

A avaliação das mudanças foi realizada utilizando-se a escala de concordância tipo Likert com as assertivas relacionadas a seguir, na Tabela 3. Pode-se observar nesta tabela que os entrevistados reconhecem a importância do celular como contribuição para a comunicação propriamente 
Tabela 1 - Perfil demográfico da amostra

\begin{tabular}{|c|c|c|}
\hline Perfil da amostra & $2006(\%)$ & $2011(\%)$ \\
\hline \multicolumn{3}{|l|}{ Sexo } \\
\hline Feminino & 55 & 57 \\
\hline Masculino & 45 & 43 \\
\hline \multicolumn{3}{|l|}{ Classe socioeconômica } \\
\hline C & 66 & 73 \\
\hline D & 34 & 27 \\
\hline \multicolumn{3}{|l|}{ Faixa etária } \\
\hline Até 15 anos & 3 & 8 \\
\hline 16 a 24 anos & 27 & 33 \\
\hline 25 a 29 anos & 22 & 16 \\
\hline 30 a 39 anos & 26 & 22 \\
\hline 40 a 49 anos & 13 & 12 \\
\hline 50 a 60 anos & 6 & 7 \\
\hline Acima de 60 anos & 3 & 2 \\
\hline \multicolumn{3}{|l|}{ Escolaridade } \\
\hline Até Ensino Fundamental incompleto & 11 & 30 \\
\hline Até Ensino Fundamental completo & 20 & 21 \\
\hline Até Ensino Médio incompleto & 28 & 20 \\
\hline Até Superior incompleto & 31 & 24 \\
\hline Superior completo & 10 & 5 \\
\hline \multicolumn{3}{|l|}{ Frequência de uso } \\
\hline Diariamente & 77 & 91 \\
\hline Semanalmente & 10 & 3 \\
\hline Mensalmente & 2 & 4 \\
\hline Raramente & 11 & 2 \\
\hline
\end{tabular}

Fonte: Dados da pesquisa.

dita e para a socialização. Em relação à rapidez, facilidade, frequência e ao acesso a amigos e parentes, parece não haver dúvidas entre os entrevistados, cujos percentuais de grau de concordância superaram em 
BACHA, M. L.; FIGUEIREDO NETO, C.; SCHAUN, A.

Tabela 2 - Posse e uso do celular

(Continua)

\begin{tabular}{|c|c|c|}
\hline Perfil da amostra & 2006 & 2011 \\
\hline Possui o celular que usa & $96 \%$ & $94 \%$ \\
\hline Usam pré-pago & $89 \%$ & $6 \%$ \\
\hline \multicolumn{3}{|l|}{ Gasto com celular } \\
\hline Até $\mathrm{R} \$ 10,00$ & $7 \%$ & $10 \%$ \\
\hline $\mathrm{R} \$ 11,00$ a $\mathrm{R} \$ 30,00$ & $41 \%$ & $55 \%$ \\
\hline $\mathrm{R} \$ 31,00$ a $\mathrm{R} \$ 50,00$ & $25 \%$ & $18 \%$ \\
\hline $\mathrm{R} \$ 51,00$ a $\mathrm{R} \$ 70,00$ & $20 \%$ & $6 \%$ \\
\hline $\mathrm{R} \$ 71,00$ a $\mathrm{R} \$ 100,00$ & $3 \%$ & $4 \%$ \\
\hline $\mathrm{R} \$ 101,00$ a $R \$ 150,00$ & $3 \%$ & $3 \%$ \\
\hline $\mathrm{R} \$ 151,00$ a $\mathrm{R} \$ 200,00$ & $2 \%$ & $2 \%$ \\
\hline Acima de $\mathrm{R} \$ \mathbf{2 0 1 , 0 0}$ & & $2 \%$ \\
\hline Média ponderada & $\mathrm{R} \$ 42,39$ & $\mathrm{R} \$ 37,12$ \\
\hline \multicolumn{3}{|l|}{ Tempo de posse de celular } \\
\hline Menos de 6 meses & $32 \%$ & $5 \%$ \\
\hline Mais de 6 meses até 1 ano & $20 \%$ & $8 \%$ \\
\hline Mais de 1 ano até 2 anos & $19 \%$ & $13 \%$ \\
\hline Mais de 2 anos até 3 anos & $14 \%$ & $13 \%$ \\
\hline Mais de 3 anos até 5 anos & $7 \%$ & $22 \%$ \\
\hline Mais de 5 anos & $7 \%$ & $39 \%$ \\
\hline \multicolumn{3}{|l|}{ Troca de aparelho } \\
\hline Nenhuma & $60 \%$ & $15 \%$ \\
\hline 1 vez & $15 \%$ & $11 \%$ \\
\hline 2 vezes & $8 \%$ & $15 \%$ \\
\hline 3 vezes & $10 \%$ & $23 \%$ \\
\hline 4 vezes & $3 \%$ & $15 \%$ \\
\hline 5 vezes & $2 \%$ & $7 \%$ \\
\hline 6 vezes ou mais & $2 \%$ & $15 \%$ \\
\hline
\end{tabular}


Tabela 2 - Posse e uso do celular

(Conclusão)

\begin{tabular}{|c|c|c|}
\hline Perfil da amostra & 2006 & 2011 \\
\hline \multicolumn{3}{|c|}{ Número de aparelhos que tem ou usa } \\
\hline 1 aparelho & $88 \%$ & $71 \%$ \\
\hline 2 aparelhos & $7 \%$ & $19 \%$ \\
\hline 3 aparelhos ou mais & - & $5 \%$ \\
\hline \multicolumn{3}{|l|}{ Número de aparelhos em casa } \\
\hline Tem 1 & $42 \%$ & $7 \%$ \\
\hline Tem 2 & $27 \%$ & $31 \%$ \\
\hline Tem 3 & $23 \%$ & $31 \%$ \\
\hline Tem 4 ou mais & $8 \%$ & $31 \%$ \\
\hline \multicolumn{3}{|l|}{ Posse de aparelhos } \\
\hline Irmãos & $28 \%$ & $26 \%$ \\
\hline Pais & $23 \%$ & $38 \%$ \\
\hline Cônjuge & $17 \%$ & $34 \%$ \\
\hline Filhos & $15 \%$ & $23 \%$ \\
\hline Parentes & $6 \%$ & $10 \%$ \\
\hline Amigos & $3 \%$ & $26 \%$ \\
\hline Outros & $8 \%$ & $38 \%$ \\
\hline \multicolumn{3}{|l|}{ Indicação de operadora } \\
\hline Sim & $64 \%$ & $83 \%$ \\
\hline Não & $36 \%$ & $17 \%$ \\
\hline \multicolumn{3}{|l|}{ Para quem indicaria operadora } \\
\hline Amigos & $44 \%$ & $71 \%$ \\
\hline Familiares & $34 \%$ & $66 \%$ \\
\hline Colegas de trabalho/estudo & $16 \%$ & $34 \%$ \\
\hline Outros & $7 \%$ & $20 \%$ \\
\hline
\end{tabular}

Fonte: Dados da pesquisa.

todos os quesitos mais de $90 \%$. Entretanto, contribuições para aumento de escolaridade e qualidade do lazer parecem ser menos significativas.

É interessante ressaltar, também, que $69 \%$ concordam que a vida melhorou com celular e apenas $4 \%$ acreditam que piorou. Para esses, o 
Tabela 3 - Mudanças percebidas

\begin{tabular}{|c|c|c|}
\hline Depois que comecei a usar o celular... & $\begin{array}{c}2006 \\
\text { Grau de } \\
\text { concordância } \\
(\%)\end{array}$ & $\begin{array}{c}2011 \\
\text { Grau de } \\
\text { concordância } \\
(\%)\end{array}$ \\
\hline \multicolumn{3}{|l|}{ Contribuições do celular para a comunicação/ socialização } \\
\hline ... posso me comunicar com mais rapidez & 74 & 96 \\
\hline ... posso me comunicar com mais frequência & 68 & 96 \\
\hline ... posso me comunicar com mais facilidade & 65 & 94 \\
\hline ... dou/recebo recados importantes & 60 & 91 \\
\hline ... falo mais com meus parentes/familiares & 60 & 90 \\
\hline ... falo mais com meus amigos & 60 & 95 \\
\hline ... posso mandar mensagens & 57 & 91 \\
\hline ... falo com meus amigos a qualquer hora & 57 & 92 \\
\hline \multicolumn{3}{|l|}{ Contribuições do celular para o lazer e vida afetiva } \\
\hline ... tive mais vontade de sair de casa, de passear & 44 & 41 \\
\hline ... tive vontade de ir a eventos, teatro, cinema, shows & 38 & 31 \\
\hline $\begin{array}{l}\text {... arrumei namorado(a), noivo(a), cônjuge } \\
\text { Contribuições do celular para o trabalho }\end{array}$ & 29 & 25 \\
\hline ... tive vontade de ganhar mais & 39 & 24 \\
\hline ... tive vontade de trabalhar & 37 & 20 \\
\hline $\begin{array}{l}\text {... tive vontade de mudar de emprego } \\
\text { Contribuições do celular para o estudo/aprendizagem }\end{array}$ & 27 & 11 \\
\hline ... mais vontade de estudar & 39 & 14 \\
\hline ... vontade de aprender a usar o computador & 33 & 22 \\
\hline ... vontade de fazer cursos & 35 & 13 \\
\hline ... vontade de ter um computador & 31 & 23 \\
\hline ... vontade de aprender inglês & 21 & 12 \\
\hline ... vontade de fazer faculdade & 21 & 9 \\
\hline
\end{tabular}

Fonte: Dados da pesquisa. 
principal problema se refere à perda de privacidade: "piorou porque a gente fica sem privacidade (69\%)"; "piorou porque as pessoas me acham com mais facilidade para resolver problemas" (75\%); "piorou porque as pessoas me acham a qualquer hora, em qualquer situação (75\%)"; "piorou porque as pessoas me acham em qualquer lugar (81\%)"; "piorou porque as pessoas me acham com mais facilidade (69\%)".

Em contrapartida, alguns aspectos negativos podem ser observados quanto à adoção do celular no cotidiano dessas pessoas. Entre esses aspectos, o mais grave refere-se à questão da escolaridade, todos os itens tiveram índices menores entre 2006 e 2011, sendo que o mais significativo diz respeito à vontade de estudar. Em 2006, 39\% indicavam que essa vontade aumentava, mas em 2011 apenas 14\% apresentavam vontade de melhorar os estudos. Enquanto em 2006 21\% tinham vontade de fazer uma faculdade, em 2011 o percentual caiu para 9\%. Tais achados demonstram que o acesso ao consumo e a uma maior facilidade de comunicação não são fatores relevantes para uma mobilidade em termos educacionais. Com relação ao emprego ou trabalho, os percentuais podem estar refletindo as altas taxas de emprego e os aumentos reais obtidos nos últimos anos (RIBEIRO, 2012).

\section{Comunicação estratégica das marcas de telefonia móvel no Brasil}

Para estabelecer uma comunicação eficaz com os consumidores, as empresas desenvolvem campanhas publicitárias com grande divulgação em todos os tipos de mídia. De acordo com pesquisa da GfK (2010), o celular aparece em primeiro lugar como o gadget eletrônico mais importante para o consumidor brasileiro. Os motivos dessa preferência indicam que ele é acessível em termos de preço e de usabilidade (LORENZINI; MACHADO, 2011). Vale observar que o segmento de telefonia móvel é hoje um dos que permite maior espectro de classe social, idade e gênero. Os autores analisaram a comunicação estratégica em campanhas publicitárias desenvolvidas pelas quatro principais marcas de telefonia móvel do país: Vivo, Tim, Claro e CorpCo.

A pesquisa foi baseada em comerciais produzidos pelas operadoras e divulgada na mídia em 2010. No estudo, observa-se que o consumo construído pela experiência de compra e venda característica do processo de troca se liberta do simples ato comercial para adquirir o patamar simbólico. Para Lorenzini e Machado (2011, p. 801), "com seus recursos de persuasão, tende 
a tornar a comunicação da marca com o público lucrativa e reproduzível em diferentes meios e formatos. Define, pois, domínios simbólicos, que mantêm o contínuo contato da marca com seus consumidores". Os resultados dessas análises apresentam características muito reveladoras quanto ao posicionamento de comunicação das operadoras de telefonia móvel no Brasil em 2010, e que continuaram no ano de 2011, já que os comerciais veiculados na mídia mantiveram os conceitos-chave identificados na pesquisa.

Segundo Lorenzini e Machado (2011), a empresa Claro apresenta como tema principal da sua comunicação o conceito de escolha. $\mathrm{A} \mathrm{Oi}^{1}$ se utiliza de uma linguagem mais caricatural, referenciando sempre as outras operadoras de modo satírico, o posicionamento sintetiza-se pelo conceito de simplicidade. No caso da empresa Tim, o que chama atenção no estudo é a forma mais séria de abordar os assuntos usando de "jogos de oposição de ideias", em que o conceito fundamental é a expansão de fronteiras. A empresa Vivo apresenta o conceito-chave de conectividade, e se posiciona no cenário oferecendo soluções. Um fato relevante observado na pesquisa é a que a liberdade e a mobilidade foram identificadas como temas-chave presentes em todos os comerciais estudados por Lorenzini e Machado (2011). No estudo, essas duas temáticas emergem em comum, muito embora sejam abordadas de formas diversas pelas quatro principais operadoras, indicando uma perspectiva de comunicação com o mercado focada no poder que o consumidor passou a ter, a partir da tecnologia digital, configurada no celular de escolha.

Contudo, é importante ressaltar que a ideia de mobilidade e conectividade pode ter sua origem em uma experiência de consumo que não foi vivida pelo consumidor de baixa renda. A ideia de mobilidade nasce da libertação em relação ao telefone fixo. Muitos desses consumidores, entretanto, jamais tiveram um aparelho fixo. Já quando se fala em conectividade, dois valores estão em tela: a habilidade para acessar sites, e-mails e redes sociais e a possibilidade de trocas de arquivos de matrizes distintas. Desenhase, então, um cenário de uso de smartphones em que há trocas de dados. Nem sempre, contudo, o usuário de baixa renda, em especial os mais velhos (BACHA et al., 2013), se utiliza do celular com esses fins. Pode-se considerar que as operadoras anunciantes estão mirando à frente, quando os usuários estiverem comprando equipamentos mais sofisticados e operando-os com competência, ou, ainda, que as operadoras estão mirando em um público, mas emitindo mensagens impróprias para esse público.

1 Em 2011, a CorpCo ainda se denominava Oi. 
De acordo com Rocha e Pereira (2012, p. 4), "a narrativa publicitária incorpora um complexo conjunto de representações, expressa identidades, diferenças, subjetividades, comportamentos, projetos, relações, define capitais sociais". Diante dessa perspectiva, os autores concluem que a publicidade oferece um caminho, o "mapa classificatório central", regulando várias esferas da experiência social na cultura contemporânea, considerando-se que "o consumo perpassa a vida social do nosso tempo com uma força que poucos fenômenos possuem" (ROCHA; PEREIRA, 2012, p. 4).

A partir desses resultados, na perspectiva dos autores com os quais o estudo dialoga, pode-se admitir que o uso e a posse do celular passem a ser fator de grande relevância para a inclusão social e digital, envolvendo acesso à tecnologia, mas igualmente para a maior inserção no contexto simbólico do consumo midiático de socialização do indivíduo de baixa renda. Entendendo-se a publicidade como uma fonte significativa de construção de cultura popular, o universo de conceitos que são associados às marcas das operadoras projeta um usuário futuro, desejável para as operadoras, pois utilizarão mais e mais serviços oferecidos, desde que, claro, compreendam a mensagem e consigam se enxergar usando tais facilidades.

Do ponto de vista das operadoras de telefonia móvel, a pesquisa buscou em Lorenzini e Machado (2011) uma interface com os aspectos da comunicação estratégica, em que se evidenciou que as quatro maiores operadoras conseguem, com suas campanhas publicitárias, ir além de suprir as necessidades de comunicação. Ao fazer uso dos simbolismos próprios do universo da publicidade, o objetivo dessas empresas parecer ser o de formar e suscitar desejos no seu consumidor, estimulando, a todo o instante, um comunicação tecnológica, multimídia, rápida, móvel, que permite aos usuários atingir um sentimento de "liberdade" e de poder de comunicação "sem fronteiras". Lorenzini e Machado (2011, p. 809) concluem afirmando que as empresas transformaram a necessidade de comunicação em "desejo de liberdade" para se comunicar, liberdade que aparece vinculada às facilidades, vantagens e mobilidade trazida pela tecnologia. Essa propalada "liberdade", contudo, ainda está por se provar efetiva quando se trata do usuário de baixa renda. Levando em consideração que a maior parte desses consumidores trabalha em sistemas que controlam seus horários de entrada e saída do serviço, a ideia de liberdade para acessar e trabalhar pelo celular parece um tanto distante, talvez negativa, pois o obrigará a trabalhar mais do que o desejado, ou mais do que o tempo pelo qual é remunerado. Parece, contudo, que o uso do celular está mais ligado ao lazer e à inserção social do sujeito. O discurso publicitário, portanto, estaria pouco adequado a essa massa de consumidores. 


\section{Considerações finais}

O objetivo principal foi analisar as mudanças percebidas na vida dos usuários de celular de baixa renda com o uso dessa tecnologia de infocomunicação. Inicialmente, apresentou-se breve referencial teórico, completado com análises dos dados da pesquisa empírica.

Considerando-se os resultados obtidos, foi possível admitir que uma parcela significativa da população de baixa renda, usuária de telefone celular e residente no município de São Paulo, tem atitude amplamente favorável ao telefone celular, e são poucas as referências negativas.

$O$ estudo evidencia que o uso do celular é fundamental quanto aos aspectos de sociabilização e de comunicação. Assim, é possível admitir que para a população de baixa renda pesquisada o celular é fator contributivo para a inclusão social, na medida em que facilita o adensamento da malha de relações comunicativas entre as pessoas, o que pode impulsionar o indivíduo para o exercício da cidadania ativa.

Em oposição, foi possível verificar que o celular como gadget tem se demonstrado um "brinquedo" tão fascinante que os respondentes não o associam a melhoras em suas vidas afetivas, de lazer ou no trabalho. Não obstante, há grande concordância de que a vida ficou mais fácil, prática e rápida com o uso desses aparelhos. Curioso contraste, uma vez que facilidade e praticidade são elementos próprios do universo do trabaIho e das relações sociais e afetivas. A hipótese é a de que a miríade de possibilidades que o uso do celular oferece chega a confundir e ofuscar o usuário de baixa renda. São tantas as possibilidades que esse usuário se atém a mais prática. A inclusão social, o existir na comunidade tem extrema importância para a população de baixa renda e o celular se tornou, então, uma máquina para adquirir status social.

A mudança possibilitada pelo celular pode ser vista até mesmo na música popular. O artista Seu Jorge, que ganhou fama nos anos 1990 com o grupo Farofa Carioca, emplacou um sucesso, a música São Gonça, na qual interpreta um rapaz que tenta justificar para a namorada o fato de não ter telefonado com a seguinte estrofe:

Mas tente compreender

Morando em São Gonçalo você sabe como é

Hoje à tarde a ponte engarrafou

E eu fiquei a pé

Tentei ligar pra você

O orelhão da minha rua 
Estava escangalhado

Meu cartão tava zerado

Mas você crê se quiser... (SEU JORGE, 2012).

Essa canção, do ano de 1997, remete ao tempo em que o popular de baixa renda dependia da telefonia pública para comunicar-se. Passados 12 anos, o mesmo artista grava com Ana Carolina, em 2009, o samba denominado Tá rindo, é?, que demonstra outra realidade no uso da telefonia:

Ah, recebi um torpedo da telefonia no meu celular Prometendo desconto às três da manhã se eu puder falar.

Mas de madrugada, quem vai me atender, quem vai me ligar? (Eu hein!) (CAROLINA; MOMBAÇA; VILLEROY, 2009).

Nota-se a mudança conceitual no uso do sistema de telefonia pelo brasileiro. No primeiro caso, a dependência do telefone público (quebrado) impediu o contato entre os namorados; no segundo, a possibilidade de contato telefônico não é apenas possível, mas permite ao usuário escolher um plano mais barato (desde que fale de madrugada). Com ironia, o samba demonstra a fragilidade da oferta da operadora, mas também mostra que a facilidade de contato telefônico evoluiu brutalmente em 12 anos. Da impossibilidade absoluta à variedade de opções na escolha do plano da operadora, e mesmo no uso de mensagens de texto, o celular passa a significar efetiva vantagem para o consumidor de baixa renda.

Contudo, as demais possibilidades que o celular oferece - como a facilidade de acesso para informações profissionais, para o desenvolvimento pessoal e acadêmico, a praticidade do contato profissional e os infindáveis jogos afetivos que podem acontecer por meio dos recursos como o envio de texto, fotos e imagens para a pessoa amada - não apareceram como um uso efetivo por esse público. Pode-se arriscar a dizer que, ao mesmo tempo em que tem na comunicação seu elemento mais encantador, o celular é também um equipamento que suga o indivíduo para dentro da rede, e nela, como um voyer, ele se diverte e absorve o mundo, sem, contudo, participar dele. Não são poucos os que acessam as redes sociais, mas nelas não postam imagens ou comentários. Restringem-se a olhar e, no máximo, curtir um post, enquanto devoram o mundo ao seu redor. Nesse sentido, essa máquina, feita para aproximar e facilitar o relacionamento das pessoas, acaba por afastá-las ao imergir cada um em uma viagem pessoal de observação da vida alheia. 
Este estudo chega às conclusões aqui expostas, mas não encerra a discussão a respeito do fenômeno do celular como o gadget da inclusão social na baixa renda em São Paulo, que, de fato, introduz o sentido de liberdade e conectividade. As mudanças são constantes e ainda existem poucas reflexões acadêmicas com enfoque sistemático sobre esses aspectos.

\section{Referências}

ALMEIDA, I. Nova classe média... Será nova? Revista ESPM, p. 100-108, jul./ago. 2011.

ALMEIDA PRADO, K. P. L. A preferência da marca no processo de decisão de compra: um estudo exploratório no segmento de baixa renda. 2008. Tese (Doutorado em Administração) - Universidade de São Paulo, São Paulo, 2008.

ARAÚJO, F. F.; VANZELLOTTI, C. A; LEVY, B. P. Objetos amados em lares de baixa renda: um estudo exploratório sobre o comportamento de consumo de jovens. In: ENCONTRO DE MARKETING DA ANPAD, 5., Curitiba, 2012. Anais... Curitiba: Anpad, 2012. Disponível em: <http://www.anpad.org.br/diversos/trabalhos/EMA/ ema_2012/2012_EMA350.pdf>. Acesso em: 8 dez. 2013.

ASSOCIAÇÃO BRASILEIRA DE EMPRESAS DE PESQUISA - ABEP. Critério de Classificação Econômica Brasil. 2010. Disponível em: <http://www.abep.org/novo/ Content.aspx?SectionID=84 >. Acesso em: 10 maio 2010.

BACHA, M. L; VIANNA, N.; SANTOS, J. Celular e inclusão social. São Paulo: Fapesp; Pleiade, 2009.

BACHA, M. L. et al. Socorro, os ícones sumiram! Smartphone touchscreen e usuários adultos de idade avançada. Trabalho apresentado ao Simpósio de Excelência em Gestão e Tecnologia da Associação Educacional Dom Bosco, Resende, 2013.

BACHA, M. L.; SCHAUN, A. A posse do celular e o self estendido: um estudo longitudinal baseado em atitudes da baixa renda de São Paulo, Brasil. In: SIMPÓSIO EM TECNOLOGIAS DIGITAIS E SOCIABILIDADE - SIMSOCIAL, 2011, Salvador. Anais... Salvador, 2011.

BLACKWELL, R; MINIARD, P.; ENGEL, J. Comportamento do consumidor. São Paulo: Thomson, 2005.

BRASILEIROS são os que mais querem comprar smartphones, indica ranking de países. UOL notícias, 10 out 2012. Disponível em: <http://tecnologia.uol.com.br/ noticias/redacao/2012/10/10/brasileiros-sao-os-que-mais-querem-comprar-smartphones-indica-ranking-de-paises.htm>. Acesso em: 15 jan. 2013. 
BUZATO, M. K. Inclusão digital como invenção do quotidiano: um estudo de caso. Revista Brasileira de Educação, v. 13, n. 38, p. 325-413, maio/ago. 2008. Disponível em: <http://www.scielo.br/pdf/rbedu/v13n38/10.pdf>. Acesso em: 10 out. 2013.

CANCLINI, N. Consumidores e cidadãos. Rio de Janeiro: Ed. UFRJ, 1999.

CAROLINA, A.; MOMBAÇA; VILLEROY, A. Tá rindo, é? Intérprete: Ana Carolina e Seu Jorge. In: ANA CAROLINA. Nove. Sony, 2009. Disponível em: <http://www.vagalume. com.br/ana-carolina/ta-rindo-e.html>. Acesso em: 18 dez. 2013.

CHAUVEL, M. A.; MATTOS, M. P. A. Z. Consumidores de baixa renda: uma revisão dos achados de estudos feitos no Brasil. Cadernos EBAPE.BR, v. 6, n. 2, p. 1-17, jun. 2008.

DOUGLAS, M.; ISHERWOOD, B. O mundo dos bens: uma antropologia do consumo. Rio de Janeiro: Ed. UFRJ, 2004.

FUTURECOM. Brasil já é o quarto maior mercado de mobilidade no mundo. 2012. Disponível em: <http://itweb.com.br/61854/brasil-ja-e-o-quarto-maior-mercado-de-mobilidade-no-mundo>. Acesso em: jan. 2013.

GFK. Celular lidera intenção de troca entre eletroeletrônicos. 2010. Disponível em: <http://www2.uol.com.br/canalexecutivo/notas11/1901201116.htm>. Acesso em: 15 mar. 2011.

GOUVEIA, I. Tecnologias de comunicação em comunidades de baixa renda. 2004. Dissertação (Mestrado em Comunicação) - Universidade Federal do Rio de Janeiro, Rio de Janeiro, 2004.

HALL, S. A identidade cultural na pós-modernidade. Rio de Janeiro: DP\&A, 2001.

IBGE. Síntese de indicadores. 2013. Disponível em: <http://www.ibge.gov.br/estadosat/temas.php?sigla=rs\&tema=pnad_2012>. Acesso em: 20 set. 2013.

IBOPE MÍDIA. Celular é mais importante que computador com internet. 2009. Disponível em: <http://www.tonsdeazul.com/ celular-e-mais-importante-que-computador-com>. Acesso em: 15 jul. 2010.

IPSOS. Comunicaciones móviles y desarrollo en América Latina - relatório final dos seis estudos de caso realizados na região metropolitana de São Paulo. 2008. Disponível em: <http://www.ipsos.cl/documentos/Ipsos_MediaCT_Estudio_IVR_ Portabilidad_Numerica.pdf>. Acesso em: 15 jun. 2013.

LEMOS, A. Cibercultura e mobilidade: a era da conexão. Razon y palavra, 2004. Disponível em: <http://www. razonypalabra.org.mx>. Acesso em: 10 jan. 2013. 
LEX, S. Inovação tecnológica e vantagens competitivas sustentáveis no setor de telefonia celular do Brasil: um estudo sobre a interveniência da convergência digital. 2008. Tese (Doutorado em Administração) - Universidade Presbiteriana Mackenzie, São Paulo, 2008.

LORENZINI, G. C.; MACHADO, M. B. A evolução estratégica das marcas de telefonia móvel no mercado brasileiro. In: ENCONTRO DE PESQUISADORES EM PUBLICIDADE E PROPAGANDA, 2., 2011, São Paulo. Anais... São Paulo: Pró-PesqPP, 2011.

MALHOTRA, N. K. Pesquisa de marketing: uma orientação aplicada. 3. ed. Porto Alegre: Bookman, 2001.

MAZMANIAN, M.; ORLIKOWSKI, W.; YATES, J. Crackberrys: exploring the social implications of ubiquitous wireless e-mail device. 2006. Disponível em: </http://www. emeraldinsight.com/journals.htm?articleid...show shtm>. Acesso em: 20 jan. 2013.

OBSERVADOR BRASIL. Observador Brasil 2011: classes sociais não formam mais uma pirâmide. Disponível em: <http://www.infomoney.com.br/onde-investir/ noticia/2066696/observador-brasil-2011-classes-sociais-nao-formam-mais-uma-piramide>. Acesso em: 20 jan. 2013.

PAVÃO, A.; LIMA, M. Quando o encantamento pela ciência produz frutos de cidadania. In: MATOS, C. Ciência e inclusão social. São Paulo: Terceira Margem, 2002. p. 41-48.

RIBEIRO, F. Taxa de desemprego fica em 5,4\% em setembro, diz IBGE. 2012. Disponível em: <http://oglobo.globo.com/economia/taxa-de-desemprego-fica-em-54-em-setembro-diz-ibge-6521702\#ixzz2KRe0KOru>. Acesso em: 20 jan. 2013.

ROCHA, A. M. C. et al. Adoption and use of technology by low-income young consumers: the case of cellular phones. C. K. Prahalad's legacy: business for poverty alleviation, San Diego, Estados Unidos, 1, 2011, p. 1-13.

ROCHA, E.; PEREIRA, C. Os paradoxos, a magia e a razão prática: aproximações possíveis entre antropologia, comunicação e mercado. In: ENCONTRO DA COMPÓS, 21., 2012, Juiz de Fora. Anais... Juiz de Fora: Universidade Federal de Juiz de Fora, 2012.

SANT'ANNA, H.; GARCIA, A. Tecnologia da comunicação e mediação social: o papel da telefonia celular na amizade entre adolescentes. Interação em Psicologia, v. 15, n. 1, p. 37-50, 2011.

SCHAUN, A. et al. O celular como supermidia: consumo, status e sedução. In: SEMINÁRIO INTERNACIONAL DE COMUNICAÇÃO, 10., 2009, Porto Alegre, v. 1. 
SEU JORGE. São Gonça. Intérprete: Seu Jorge. In: SEU JORGE. Músicas para churrasco. 2012. v. 1. Disponível em: <http://www.seujorge.com/musica/>. Acesso em: out. 2013.

SIKDAR, A.; VEL, P. Getting the customer interested in your innovation: role of distribution and promotion strategies. Business Strategy Series, v. 11, n. 3, p. 158-168, 2010.

SILVA, S. R. "Eu não vivo sem celular": sociabilidade, consumo, corporalidade e novas práticas nas culturas urbanas. Intexto, v. 2, n. 17, p. 1-17, jul./dez. 2007.

SOLOMON, M. Comportamento do consumidor: comprando, consumindo e sendo. Porto Alegre: Bookman, 2005.

SOUZA, A.; LAMOUNIER, B. A classe média brasileira: ambições, valores e projetos de sociedade. Rio de Janeiro: Campus, 2010.

SPLITZ, R. O uso inconsciente da tecnologia no cotidiano. Strategic Design Research Journal, v. 1, n. 1, jul./dez. 2008. Disponível em: <http://www.unisinos.br/sdrj/ index.php? e=1\&s=9\&a=53>. Acesso em: 10 jan. 2013.

TELECO. Estatísticas de celulares no Brasil. 2013. Disponível em: <http://www.teleco.com.br/ncel.asp>. Acesso em: ago. 2013.

TREVISAN, N. Por mares nunca dantes navegados: estudos para a inclusão da população de baixa renda na sociedade da informação. 2005. Dissertação (Mestrado em Engenharia) - Universidade de São Paulo, São Carlos, 2005.

Recebido: $26 / 08 / 2013$

Received: 08/26/2013

Aprovado: $21 / 10 / 2013$

Approved: 10/21/2013 